\title{
Employees' evaluative repertoires of tourism and hospitality jobs
}

Anna Schneider

Department for Organization and Learning, Universität Innsbruck, Innsbruck, Austria, and

Corinna Treisch

Department of Accounting, Auditing and Taxation, Universität Innsbruck, Innsbruck, Austria

\begin{abstract}
Purpose - This paper aims to examine employees' evaluative repertoires of tourism and hospitality jobs and segments them based on a set of job attribute preferences. Understanding the social-cultural underpinnings of employees' job preferences is vital if employers are to overcome the challenging task of finding and retaining talented employees in the tourism and hospitality industry.

Design/methodology/approach - A discrete-choice experiment with waiters, barkeepers, cooks and front-desk employees working in the Tyrolean tourism industry was conducted. Employees were categorized into distinct segments using a hierarchical Bayesian analysis and a cluster analysis.

Findings - Results show that flexible working hours and the ability to balance professional and private aspirations are the most important job attributes for employees. Overall, the evaluative repertoires of the "green" and "domestic (family)" conventions are most prevalent.

Research limitations/implications - This study contributes to literature on talent management by providing insights into employees' evaluations of jobs and their evaluative repertoires embedded in the broader social-cultural context.

Practical implications - Industry representatives and employers can adapt their recruiting and retention strategies based on employees' job preferences.

Social implications - Adapting job attributes according to employees' evaluative repertoires helps to ensure the long-term sustainability of the industry workforce.

Originality/value - Applying the Economics of Convention (EC) perspective, combining organizational job attributes and socially embedded evaluative repertoires provides a new approach to analysing and understanding employees' job preferences.

Keywords Cluster analysis, Choice-based conjoint analysis, Hospitality employees, Job evaluation, Economics of Convention, Job preferences, Evaluative repertoires, Tourism and hospitality industry, Discrete-choice experiment
\end{abstract}

Paper type Research paper

\section{Introduction}

Working conditions, both anticipated and experienced, play an important role in employees' choice of a profession or job or their decision to change it, especially in the tourism and

(C) Anna Schneider and Corinna Treisch. Published by Emerald Publishing Limited. This article is published under the Creative Commons Attribution (CC BY 4.0) licence. Anyone may reproduce, distribute, translate and create derivative works of this article (for both commercial and noncommercial purposes), subject to full attribution to the original publication and authors. The full terms of this licence may be seen at http://creativecommons.org/licences/by/4.0/legalcode

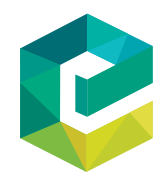

International Journal of Contemporary Hospitality Management Vol. 31 No. 8,2019 pp. 3173-3191
Emerald Publishing Limited 0959-6119 DOI 10.1108/IJCHM-08-2018-0675 
IJCHM 31,8

hospitality industry (Richardson, 2009; Penny Wan et al., 2014; Schoffstall and Arendt, 2016; Park et al., 2017). Although employers determine (anticipated) working conditions (Ladkin and Buhalis, 2016), these conditions are also situated within broader societal perceptions of the reputation or status of an industry, job or profession (Kusluvan and Kusluvan, 2003; Blomme et al., 2008; Ramakrishnan and Macaveiu, 2019). The attractiveness of a job and how satisfying it is to employees, however, varies according their expectations and aspirations (Charlesworth et al., 2014; Muñoz de Bustillo et al., 2011). Although some insightful studies explain these different employee perceptions in terms of worker characteristics (Knox et al., 2015; see also Kong et al., 2018 for an overview), few studies have sought to analyze how tourism and hospitality employees assess jobs through evaluative repertoires related to broader socialcultural values. This study seeks to provide a more comprehensive understanding of tourism and hospitality employees' job preferences by identifying employees' ideal and preferred job attribute constellations and explaining them in terms of societal values.

To better understand employees' assessments, the study draws on the Economics of Convention (EC) perspective developed by Boltanski and Thévenot (2006). EC's central idea is that individuals refer to various conventions (higher order principles such as societal values) when evaluating practices such as job attributes. With this perspective, this study assumes that employees make use of evaluative repertoires rooted in societal values (conventions) when evaluating jobs. Conjoint and cluster analysis reveals the job attributes that employees find attractive when evaluating job descriptions and the societal values that influence how they evaluate these job attributes. Accounting for employees' evaluative repertoires from an EC perspective allows for an understanding of employees' job attribute preferences from a social-cultural embedded perspective.

The study setting is the Tyrolean (North and South Tyrol) Alpine tourism and hospitality industry. The terms "Tourism" and "hospitality" are used interchangeably (Nykiel, 2005), while acknowledging that guests may also be business travellers (Okumus et al., 2010), not tourists. In this study, though, this might be less the case. The industry is seasonal (dominant winter season and a shorter summer season) and decentralized (remote valleys) and consists mostly of small- and medium-sized family-owned-and-operated organizations (Kallmuenzer, 2018). The tourism and hospitality industry in this region is important to the economy: it represents 16 per cent of regional GDP and employs almost a quarter of the region's workforce (Eurostat, 2018). Despite this importance, bars, restaurants and hotels struggle to find and hire adequate staff, significantly constraining the industry's economic growth (AMS, 2015). In 2015, the greatest staff shortages in Austria were for cooks and waiters (AMS, 2015). To better understand the job attributes employees in this region and industry are looking for, this study empirically focuses on waiters/barkeepers, cooks and front-desk employees, all of whom face a multitude of societal demands from different stakeholders (family, peers, previous employers, teachers, the media and the public).

\section{Literature review}

\subsection{Evaluation of tourism and hospitality jobs}

The tourism and hospitality industry is concerned about its poor reputation (Blomme $e$ al., 2008; Ramakrishnan and Macaveiu, 2019) because of its low wages, unsociable working hours, limited career-advancement possibilities and low-skilled tasks (Richardson, 2009; Kong et al., 2018). At the job level (McPhail et al., 2015; Schoffstall and Arendt, 2016), job satisfaction is driven by career-advancement opportunities, variety and control of tasks and positive workplace relationships, whereas their absence, combined with long working hours and physically demanding and hazardous tasks, causes employees to leave (Davidson et al., 2011). At the organizational level, organizational socialization tactics (Song et al., 2015) 
fostering a person-organization fit (Song and Chathoth, 2011) enhance job satisfaction, whereas employees' overall job embeddedness (Robinson et al., 2014), job involvement and organizational commitment (Zopiatis et al., 2014) reduce their intentions to leave.

When identifying what makes a job attractive and satisfying, some scholars consider employees' expectations and aspirations (such as the possibility for self-actualization, see Park et al., 2017) to be more decisive than the job attributes themselves (Charlesworth et al., 2014; Muñoz de Bustillo et al., 2011). They suggest that individuals' job preferences (Holman, 2013) are shaped by organizational and industry culture (Tepeci and Bartlett, 2002), as well as by the broader social-cultural context (Holman, 2013; Sledge et al., 2008). This view implies that job assessment is a subjective process based on individual preferences that must consider the embeddedness of working life within general societal value constellations (Knox et al., 2015; Baum, 2015).

Talent management literature (Deery and Jago, 2015; Baum, 2008; Deery, 2008) emphasizes that organizational and industry attributes, such as an eco-friendly image (Yen et al., 2013) or CSR activities (Ko et al., 2019; Day et al., 2013), and individual employee characteristics (Bellou et al., 2018) are factors crucial for employees' job attraction, satisfaction and retention However, this research has studied these attributes and characteristics in isolation. So far, it has not included societal values (Tepeci and Bartlett, 2002, for an exception) when analysing employees' job attribute preferences. Including these values makes possible an integration of individual preferences and the evaluation of organizational and industry attributes. This paper argues that the values, norms and beliefs embedded in a wider societal context play an important role in employees' evaluation of jobs and seeks to explain job attribute preferences by recognizing employees as socially embedded individuals. The study aims to identify employees' ideal and preferred job attribute constellations and explain them in terms of societal values. It is relevant because tourism and hospitality employers play a decisive role in shaping their organizations and jobs to foster person-organization fit (Song and Chathoth, 2011) and employees' job embeddedness (Robinson et al., 2014), thus making these jobs more attractive. To account for this, this paper studies employees' evaluations of jobs (their evaluative repertoires) from an EC perspective.

\subsection{Evaluative repertoires: the Economics of Conventions perspective}

An EC perspective postulates that people need to interpret the meaning of job attributes because these attributes are ambiguous. Boltanski and Thévenot (2006) proposed that conventions, or "higher order principles" such as societal values, serve as reference points that allow individuals to interpret and evaluate practices such as job attributes. For example, "career development" can have considerably different meaning depending on what convention is used to interpret it: it can be a means to earning a higher salary, as a source of self-fulfilment or as a symbol of status and reputation. By choosing their "ideal" job description, employees reveal their "ideal-typical" convention for their practical reality (Diaz-Bone, 2011); that is, the conventions they regard as important and the expectations they have of their employer (Pernkopf-Konhäusner and Brandl, 2011). In each convention, individuals evaluate things, activities and people differently and attribute them different value and worth, rendering the EC a micro-perspective of articulated interests embedded within a broader social-cultural context (Pernkopf-Konhäusner and Brandl, 2011; Brandl et al., 2019).

Four conventions, market, family (domestic), fame (Boltanski and Thévenot, 2006) and green (Thévenot et al., 2000) inform the analysis of employees' job preferences and comprise their evaluative repertoires. In theory, all conventions are equally available yet each is mutually exclusive. These conventions depict the multitude and complexity of different societal demands in which organizations and employees are embedded (Thévenot, 2001).
Employees' evaluative repertoires

3175 
IJCHM 31,8

Thévenot (2001) described the market and the family (domestic) conventions as most prominent in organizational settings. To account for the specific characteristics of the Alpine tourism and hospitality industry, the fame and the green conventions were also included. Fame here refers to the importance for an organization that it is well known and has a good reputation (Peters and Frehse, 2011), whereas green refers to the importance of operating sustainably and responsibly (Strobl et al., 2015; Kallmuenzer et al., 2017; Green, 2006).

Building on Boltanski and Thévenot (2006), in the market convention employees look for "the best deal" in terms of what they can get in return for their work, evaluating jobs based on a principle of economic exchange. The best situation for employees in this convention is one in which they have multiple job opportunities and are in a strong position to demand a high salary and other benefits. In the domestic (family) convention, people value authority, which is acquired and maintained by building trust through personal ties and is drawn from traditions. Experience, craftsmanship and individual company-specific know-how are important in this convention. In the fame convention, people are valuable when they have an excellent reputation, a high level of awareness or are famous. Having a reputation as a "good" cook, waiter or barkeeper is important for people in the fame convention, as they strive to make a brand name for themselves. Finally, in the green convention, people are valuable when their actions toward themselves and their environments are sustainable and responsible. Lamont and Thévenot (2000) argued that the convention people choose (what their evaluative repertoire is) is not necessarily bound to a specific individual or a group, but rather evolves with the features of their setting. These features include specific industry characteristics (working times, career opportunities) or are related to societal institutions, such as labour market flexibility, tenure or education (Pernkopf-Konhäusner and Brandl, 2011).

A few studies have used a socially embedded value framework to investigate employees' preferences (Bullinger and Treisch, 2015), but none have analyzed employees' value preferences for various job attributes in the hospitality industry. As cooks, waiters/barkeepers and frontdesk employees are most in demand in the Alpine region, this study first asks which job attributes are most important for these employees when choosing their ideal job. Second, it asks how current employees evaluate the different job attributes and which conventions are most important to them. Third, it seeks to segment employees by their value preferences.

\section{Methodology}

\subsection{The conjoint analysis method}

To examine these questions, the paper uses a choice experiment based on the conjoint analysis method developed by Luce and Tukey (1964). The advantage of this method is that it evaluates attributes simultaneously as respondents select a job description from a set of job descriptions (choice set), and thus excludes socially desirable responses. Furthermore, it provides greater face validity, as job seekers make a choice between actual job descriptions with multiple attributes. These job descriptions (Bullinger and Treisch, 2015; Montgomery and Ramus, 2011) are presented in the form of job vignettes (Aguinis and Bradley, 2014) instead of keywords. During the experiment, respondents engage in cognitive job crafting (Wrzesniewski and Dutton, 2001) as they develop their own ideal future job by selecting from different descriptions and combining their desired elements together into a purposeful entity.

From a review of the literature (McPhail et al., 2015; see Kong et al., 2018 for an overview), five job attributes were selected: notion of work, work tasks, working hours, work-related relations and career opportunities. For each attribute, four attribute levels were developed, which represent the four conventions described above. Level 1 represents the domestic (family) convention, Level 2 the market convention, Level 3 fame and Level 4 represents the green convention. The descriptions and terms used in the vignettes for each attribute level 
come from a semantic dictionary of conventions by Boltanski and Thévenot (2006) that was later extended by Patriotta et al. (2011). Attributes and levels are shown in Table I. The original individual attribute levels were written in German and were of equal length to prevent respondents from perceiving longer passages as more important than shorter ones. The English translations do not necessary maintain these equal lengths.

\begin{tabular}{ll}
\hline Attributes & Levels $^{\mathrm{a}, \mathrm{b}}$ \\
\hline
\end{tabular}

Personal notion of work

In my job, I pass on my experience to preserve the tradition of my profession and the company I work for.

In my job, I am such a valuable worker that my employer is willing to pay me a high salary.

In my job, I enjoy public recognition and a good public image (e.g. in my field, in my region, ....).

In my job, I have the possibility to experience both professional and private self-realization.

Work tasks My work tasks are specialized and require company-specific know-how that helps me fulfil these tasks.

My work tasks are appropriate relative to the salary I receive and the position I hold in the company.

My work tasks are varied and require different skills such that I can work and receive recognition in different job areas.

My work tasks can be done in the time available and require a decent amount of mental and physical energy.

Working hours $\quad$ My working hours allow me to be together with my colleagues during the entire day.

My working hours make it possible to cope with work-intensive days via overtime, which is compensated.

My working hours make it possible to work during main business hours to become acquainted with many guests.

My working hours can be scheduled flexibly for my job, myself, my family and my health.

Work-related relationships $\quad$ Work with my colleagues is based on the mutual trust which we have developed over time.

Work with my colleagues is based on a barter system, involving information, know-how and working times.

Work with my colleagues is based on the reputation one acquires in the company through one's skills.

Work with my colleagues is based on the shared appreciation of health, society and environment.

Career opportunities In the course of my career, years of experience will make me a leader among my peers.

In the course of my career, I will acquire those skills that are in great demand in the job market.

In the course of my career, I will become known for my expertise and gain public recognition.

In the course of my career, I will keep a local job, support the region and be healthy.

Notes: ${ }^{\text {a }}$ The attribute levels are based on the respective convention. The family (domestic) convention forms the first level, the market convention makes up the second level, the fame convention is depicted in the third level and the green convention is represented by the fourth attribute level; ${ }^{\mathrm{b}}$ The original German text for the individual attribute levels was written so that each was of equal length to prevent longer passages from being perceived by respondents as more important than shorter ones. These equal lengths are not necessarily reflected in the English translations

Employees' evaluative repertoires 


\section{IJCHM 31,8}

\subsection{The questionnaire, the sample and data analysis}

The choice experiment used a fractional-factorial design (Hair et al., 2010; Aizaki, 2012). The order of the job attributes in each job description was fixed - a common feature of job descriptions - yet the arrangement of the paired job descriptions in each choice set (right and left side, respectively) and the order of presentation of the choice sets was randomized to exclude lexicographic and sequencing effects.

A pre-test with a small number of cooks, waiters/barkeepers and front-desk employees was conducted to ensure that the choice tasks were understandable and represented appropriate combinations. The discrete-choice experiment was carried out between August and December 2017 with cooks, waiters/barkeepers and front-desk employees who, at the time of data collection, were employed in hotels, bars or restaurants in the German-speaking hospitality industry in Tyrol, a region with a labour shortage. The sub-regions (North Tyrol/ South Tyrol) share geography, political history, employment structure, cultural tradition and language; hence, differences between these sub-regions were not of interest.

Data were collected from 213 respondents by an interviewer handing out selfadministered, Web-based questionnaires in German. A total of 12 records were discarded because respondents worked in other jobs, and 3 records were discarded because values were missing or implausible. Respondents were first asked to imagine ideal working conditions for their current position and complete the choice task. Subsequently, data on employee satisfaction, job reputation, socialization, current job, type of current employer and completed training were collected along with other socio-demographic information, as shown in Table II.

The separate part-worths (Rossi et al., 2005) formed the basis for determining respondents' preference shares. A cluster analysis was carried out using these results to find appropriate segments who favour different job attributes and conventions. The cluster analysis is based on the part-worth estimates for the four levels of the five attributes used in the conjoint analysis. The classification uses Ward's method based on the Euclidean distance (Suzuki and Shimodaira, 2006), the standard approach for segmenting customer and employee preferences (Guillet and Kucukusta, 2016; GuillotSoulez and Soulez, 2014).

\section{Results}

\subsection{Importance of job attributes and part-worth utilities for attribute levels}

Part-worth utilities represent each individual's subjective preferences for different job attribute levels. Utility values show the impact of each of the 20 attribute levels and thus indicate employees' preference structures. If the utility value is zero, respondents have no preference. If the utility value is positive, respondents do have a certain preference. A zero on reputation and public image would signify that respondents assign a lower utility to those attributes than to others such as traditional work approach, employee recognition expressed by a high salary and balancing professional and private aspirations. It does not signify that respondents do not attribute any value to reputation and public image. Within each attribute, the level with the lowest utility is rescaled to zero, whereas the level with the highest utility is rescaled to 100 . Utility values of attribute levels and the importance of each job attribute are displayed in Table III. The estimated model is highly significant $\left(R_{C h i}^{2}=2,869,83\right.$, df $\left.=15, p \leq 0.001\right)$ and has an excellent model fit $\left(R_{M c F}^{2}=0.653\right)$.

Attribute importance is shown in Column 2 of Table III. As the part-worths are converted to a common scale, the factor with the greatest range of part-worths (from low to high) contributes most to the overall utility and hence constitutes the most important factor (Hair 


\begin{tabular}{|c|c|c|c|c|}
\hline & Sample $e^{\mathrm{a}, \mathrm{b}}$ & $\begin{array}{l}\text { Working hours and } \\
\text { work task-oriented } \\
\text { type }^{\mathrm{b}}(8.6 \%)\end{array}$ & $\begin{array}{l}\text { Personal notion of } \\
\text { work-oriented } \\
\text { type }^{\mathrm{b}}(91.4 \%)\end{array}$ & $\begin{array}{l}\text { Employees' } \\
\text { evaluative } \\
\text { repertoires }\end{array}$ \\
\hline \multicolumn{5}{|l|}{ Gender } \\
\hline Female & 62 & 53 & 62 & \multirow{4}{*}{3179} \\
\hline Male & 38 & 47 & 38 & \\
\hline No answer & 0 & 0 & 0 & \\
\hline Age of respondent & 29.55 (s.d.= 10.83) & 31.88 (s.d.= 13.20) & 29.33 (s.d.= 10.60) & \\
\hline \multicolumn{5}{|l|}{ Family status (multinominals) } \\
\hline Married/registered partnership & 13 & 24 & 12 & \\
\hline Permanent relationship & 35 & 6 & 38 & \\
\hline Child/children & 12 & 12 & 12 & \\
\hline Single & 46 & 71 & 44 & \\
\hline Divorced & 4 & 0 & 4 & \\
\hline Widowed & 1 & 0 & 1 & \\
\hline Number of children (of those who have children) & 1.91 (s.d. $=0.73$ ) & 2.00 (s.d. $\left.=0.00^{c}\right)$ & 1.90 (s.d. $=0.77)$ & \\
\hline \multicolumn{5}{|l|}{$\begin{array}{l}\text { Completed tourism-specific training } \\
\text { (multinominals) }\end{array}$} \\
\hline None & 20 & 6 & 22 & \\
\hline Apprenticeship & 29 & 29 & 29 & \\
\hline Vocational schools & 33 & 41 & 33 & \\
\hline $\begin{array}{l}\text { Vocational schools with higher education } \\
\text { entrance qualification }\end{array}$ & 7 & 12 & 7 & \\
\hline University (or equivalent) & 4 & 1 & 4 & \\
\hline Other & 14 & 24 & 12 & \\
\hline \multicolumn{5}{|l|}{ Current occupation } \\
\hline $\begin{array}{l}\text { (Statement: "How satisfied are you with your } \\
\text { current job?", 7-point Likert-type scale, } \\
7 \text { indicating "very satisfied" and } 1 \text { indicating } \\
\text { "very unsatisfied") }\end{array}$ & 5.21 (s.d.=1.49) & 5.59 (s.d.=1.28) & 5.18 (s.d.=1.50) & \\
\hline \multicolumn{5}{|l|}{ Job status } \\
\hline $\begin{array}{l}\text { (Statement: "In your opinion, how does } \\
\text { society rate your job in terms of status?", } 7 \text { - } \\
\text { point Likert-type scale, } 7 \text { indicating “very } \\
\text { high" and } 1 \text { indicating "very low") }\end{array}$ & 4.22 (s.d.=1.50) & 4.35 (s.d.=1.50) & 4.21 (s.d. $=1.50$ & \\
\hline \multicolumn{5}{|l|}{ Current job (multinominals) } \\
\hline Waiter & 43 & 24 & 45 & \\
\hline Barkeeper & 11 & 6 & 12 & \\
\hline Cook & 26 & 41 & 25 & \\
\hline Front desk & 26 & 29 & 26 & \\
\hline Other & 0 & 0 & 0 & \\
\hline Job duration in months & 34.53 (s.d. $=51.70)$ & 46.47 (s.d.= 47.89) & 33.40 (s.d. $=50.03)$ & \\
\hline \multicolumn{5}{|l|}{ Types of contract } \\
\hline Full-time contract & 80 & 88 & 79 & \\
\hline Part-time contract & 17 & 6 & 18 & \\
\hline Temporary job & 3 & 6 & 3 & \\
\hline Work hours per week & 39.24 (s.d.= 13.6) & 37.53 (s.d.= 17.95) & 39.40 (s.d.= 13.70) & Table II. \\
\hline \multirow[t]{2}{*}{ Usual overtime hours per week } & $6.55($ s.d. $=8.46)$ & 4.65 (s.d.= 6.28) & 6.73 (s.d.= 8.62$)$ & Socio-demographic \\
\hline & & & (continued) & $\begin{array}{l}\text { background of } \\
\text { cluster members }\end{array}$ \\
\hline
\end{tabular}


Overtime compensation of those who work

\section{overtime (multinominals)}

Comp time

Overtime is paid for

Overtime is included in the basic salary

Other

$\begin{array}{rrr}41^{\mathrm{d}} & 45^{\mathrm{e}} & 40^{\mathrm{f}} \\ 45^{\mathrm{d}} & 18^{\mathrm{e}} & 47^{\mathrm{f}} \\ 25^{\mathrm{d}} & 36^{\mathrm{e}} & 24^{\mathrm{f}} \\ 0^{\mathrm{d}} & 0 \mathrm{e} & \text { Of }\end{array}$

\section{Work contract}

All-year contract

Seasonal contract

Other

$\begin{array}{rrr}69 & 75 & 68 \\ 31 & 25 & 32 \\ 0 & 0 & 0\end{array}$

\section{Current employer}

Location

North Tyrol

South Tyrol

Company size

1-9 employee(s)

10-49 employees

50-249 employees

250 or more employees

Operation

Year-round operation

Seasonal operation

Management

Family members only

Family members and external managers

External managers only

$\begin{array}{lll}73 & 65 & 77 \\ 27 & 35 & 26 \\ 42 & 42 & 42 \\ 29 & 29 & 29 \\ 28 & 28 & 28\end{array}$

\section{Socialization}

Number of friends who decided for an education

in tourism at the time when I did so

$\begin{array}{lcrr}\text { None } & 40^{g} & 29^{\mathrm{h}} & 42^{\mathrm{i}} \\ \text { Some } & 48^{\mathrm{g}} & 50^{\mathrm{h}} & 48^{\mathrm{i}} \\ \text { Many } & 10^{\mathrm{g}} & 14^{\mathrm{h}} & 9^{\mathrm{i}} \\ \text { Everybody } & 2^{\mathrm{g}} & 7^{\mathrm{h}} & 2 \mathrm{i}\end{array}$

I have no education or training in tourism

Number of family members working in tourism

\begin{tabular}{|c|c|c|}
\hline Nobody & 40 & 47 \\
\hline Some & 43 & 29 \\
\hline Many & 13 & 18 \\
\hline Everybody & 3 & 6 \\
\hline y parents own a hospitality business & 15 & 35 \\
\hline y parents manage a hospitality business & 14 & 29 \\
\hline
\end{tabular}

Notes: ${ }^{a}$ Based on the 198 respondents remaining after having discarded 12 responses, as the respondents did not work in the fields under investigation and 3 responses because of missing values and implausible answers in the socio-demographic variables; ' ${ }^{\mathrm{b}}$ Mean or percentage; ${ }^{\mathrm{C}}$ Two respondents have two children each; ${ }^{\mathrm{d} B a s e d}$ on 157 respondents who work overtime; ${ }^{\mathrm{e}}$ Based on 11 respondents who work overtime; ${ }^{\mathrm{f}}$ Based on 146 respondents who work overtime; 'Based on 146 respondents who were educated or trained in tourism; ${ }^{h}$ Based on 14 respondents who were educated or trained in tourism; ${ }^{i}$ Based on 132 respondents who were educated or trained in tourism 


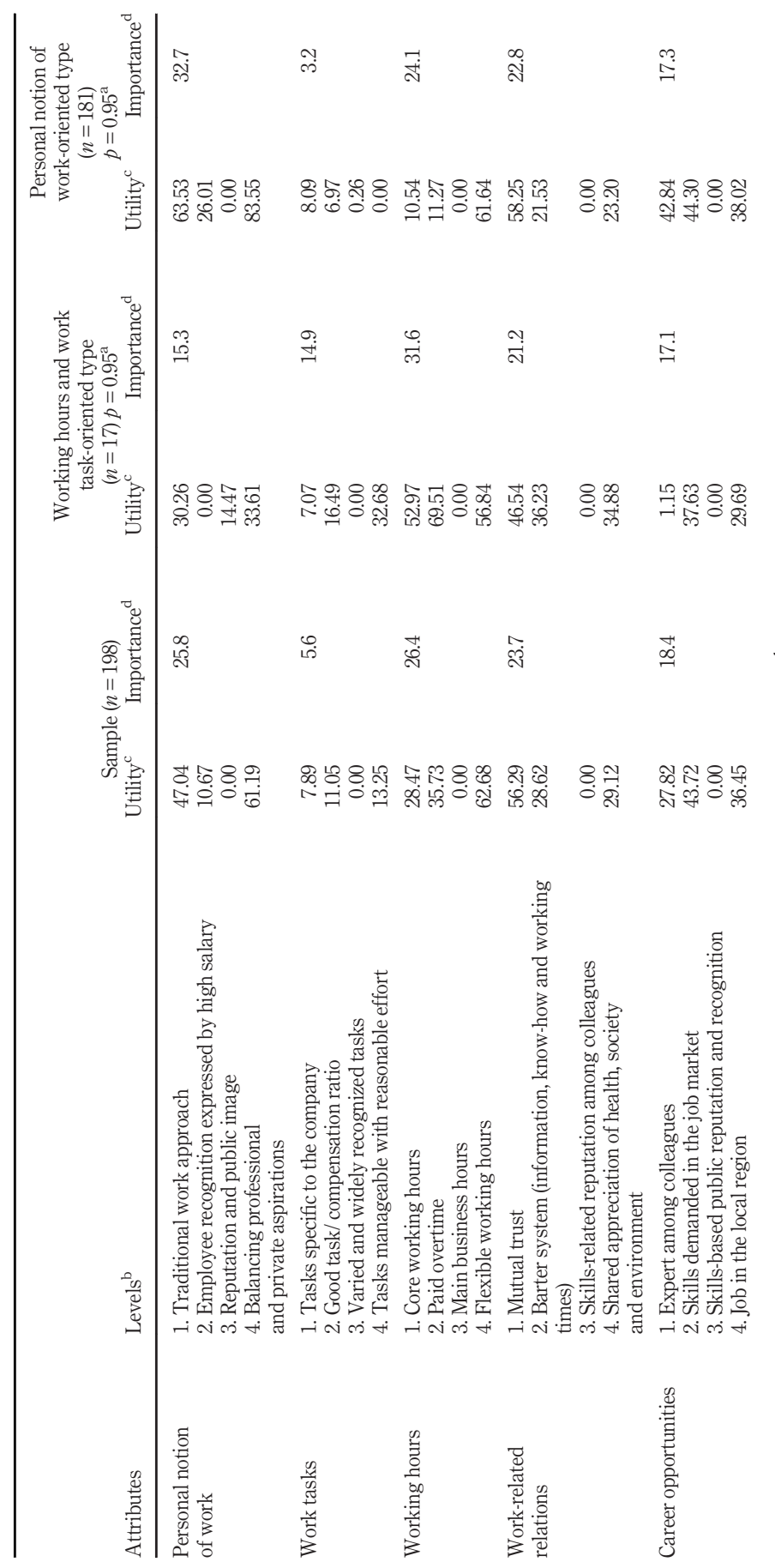

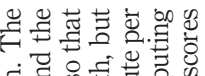

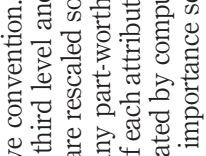

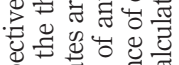

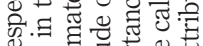
t䓎 F.․ㅡㄴ

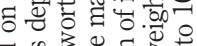

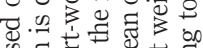

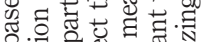

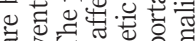
on 0 은 舟

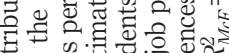

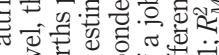

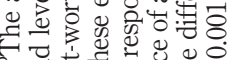
菏氙. 我 of 8 . 80 o 00

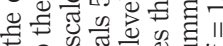

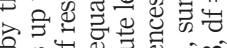
on

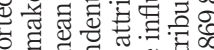

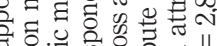
क. ․ㅡㄹ

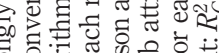

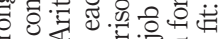

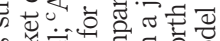

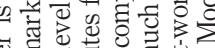

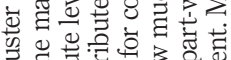

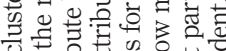
政自

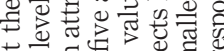

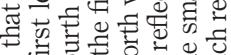
Q

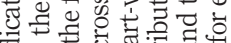

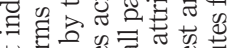

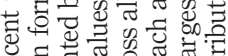
5 5

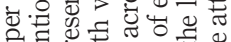

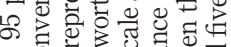
पे 웡. y. 0 政 Utility of attribute i is

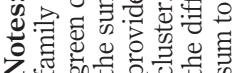
preference clusters 
IJCHM 31,8 et al., 2010). For this sample, the most important attribute of an ideal job is the "working hours" attribute, as it has the greatest range of utility values (0.00 to 62.68) and the highest importance (26.4). The second-most important attributes are "personal notion of work" (importance $=25.8$ ), "work-related relationships" and "career opportunities". Interestingly, the "work tasks" attribute is least important.

The utility values of the attribute levels are shown in Column 1 of Table III. The first attribute, "personal notion of work", is noteworthy because within this attribute, employees prefer the attribute level "balancing professional and private aspirations", which offers them 1.3 times the value of the "traditional work approach" and 5.7 times the value of "employee recognition expressed by a high salary". "Balancing professional and private aspirations" offers the second-highest utility of all attribute levels and has an impact of 12.2 per cent (61.19/500). As for the second attribute, "work tasks", employees do not show distinct preferences. Within the third attribute - "working hours" - "flexible working hours" provide 1.8 times the benefit of paid overtime and 2.2 times the benefit of a job with core working hours shared by a team. Within the "working hours" attribute, the attribute level "flexible working hours" offers the highest utility of all attribute levels, with an impact of 12.5 per cent (62.68/500). In the fourth attribute "work-related relations", "mutual trust" offers a 1.9 times greater benefit than a shared appreciation of health, society and environment, and a 2.0 times greater benefit than having a barter exchange system among colleagues. With an impact of 11.3 per cent (56.29/500), "mutual trust" offers the third-highest utility of all attribute levels. As for the fifth attribute, "career opportunities", employees value acquiring skills that are sought-after in the job market 1.2 times more than keeping a job in the local region and 1.6 times more than becoming an expert among colleagues. Acquiring skills that are sought-after in the job market offers the fourth-highest utility of all attribute levels and has an impact of 8.7 per cent $(43.72 / 500)$. The green convention is the most relevant evaluative repertoire in the hospitality and tourism industry, preferred 1.2 times more than the family (domestic) convention and 1.6 times more than the market convention. The convention of fame (attribute Level 3) is the least relevant evaluative repertoire.

\subsection{Identifying employee segments and cluster membership}

On the basis of utility values and the importance of each job attribute, a cluster analysis led to a segmentation into two clusters, "working hours and work task-oriented type" and "personal notion of work-oriented type" (Table III). Employees in each cluster have different attitudes about working hours and personal notions of work (Figure 1). In Cluster 1, the most important attribute of an ideal job is "working-hours" and the second-most important is "work-related relationships", whereas "career opportunities", "personal notion of work" and "work task" form a uniform group of less-valued job attributes. In Cluster 2, the most important attribute is "personal notion of work". "Working hours" and "work-related relationships" constitute a second group of important attributes, whereas "career opportunities" and "work task" are less important. Cluster 1 and Cluster 2 differ in distinctive ways: Cluster 1 attributes a high value to "working hours" and "work tasks", but less to "personal notion of work" (Figure 1).

Cluster 1 (8.6 per cent), the "working hours and work task-oriented type", especially favours paid overtime, mutual trust, skills demanded in the job market, balancing professional and private aspirations and tasks manageable with reasonable effort (Table III). The preference for paid overtime and tasks manageable with reasonable effort makes this cluster especially distinct from Cluster 2. The attribute levels with the highest values - paid overtime, flexible working hours and core working hours - all belong to the "working hours" attribute. 

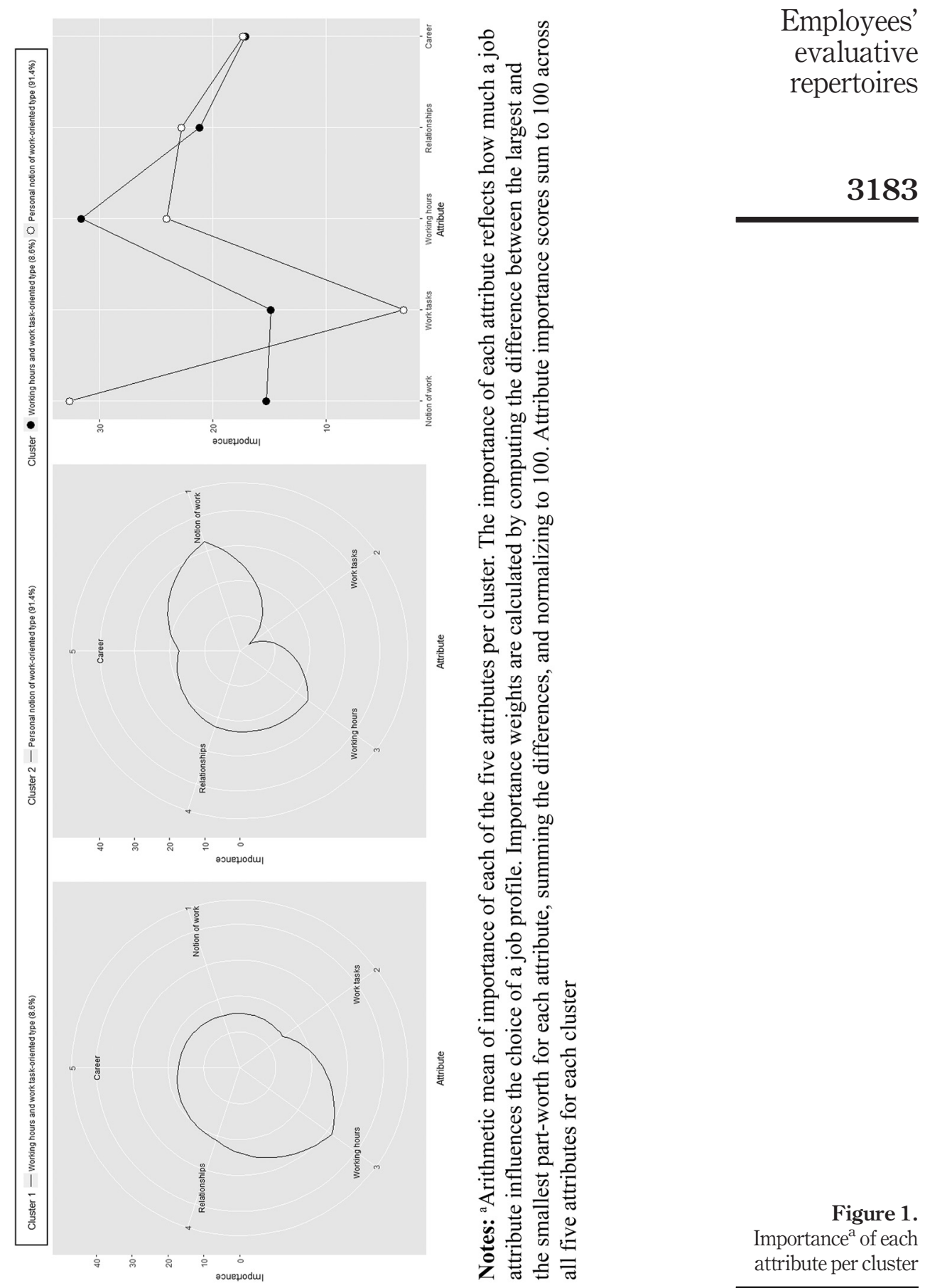

Figure 1. Importance ${ }^{\mathrm{a}}$ of each attribute per cluster 
IJCHM 31,8

3184

Cluster 2 (91.4 per cent), the "personal notion of work-oriented type", dominates the overall results displayed in Table III. In contrast to the entire sample, Cluster 2 strongly favours two job-attribute levels, namely, the "traditional work approach" and becoming an "expert among colleagues". Furthermore, Cluster 2 job attribute values differ: the most highly valued job attribute level - balancing professional and private aspirations - provides 1.9 times the benefit of acquiring sought-after job market skills. The preference for balancing professional and private aspirations and following a traditional work approach, which both belong to the attribute "notion of work", makes this cluster particularly unique (Table III).

For both clusters, the green convention is most relevant, whereas the family (domestic) convention is the second-most relevant evaluative repertoire. The third most relevant convention for both clusters is market; however, it plays a distinct role for Cluster 1. Fame is the least-relevant convention for both clusters.

The members of the two clusters were also characterized by their socio-demographic background, depicted in Table II. Cluster 1 includes a much higher proportion of cooks and a lower proportion of waiters compared with Cluster 2. Moreover, Cluster 1 members have the highest percentage of all-year contracts, longer average job duration and work slightly fewer hours per week. Members of Cluster 1 also work less overtime per week and are paid overtime less often. Members in this cluster are more likely to have parents who own or manage a hospitality business and are slightly more satisfied with their current jobs.

\section{Discussion and conclusion}

\subsection{Conclusions}

The results show that employees perceive "working hours" as the most important job attribute. In terms of employees' evaluative repertoires, when assessing "working hours", the green attribute level ("flexible working hours") is the one they value most. This finding supports studies claiming that working hours foster perceived job quality, in case employees can align working hours to fit their lifestyle (Kalleberg, 2008; Green, 2006).

"Notion of work" is the second-most relevant job attribute. Also here, the green convention, "balancing professional and private aspirations" is the most valued job attribute level. This strong preference for the green convention underscores the importance of the meaning of work (Holman, 2013; Sledge et al., 2008) for employees' job decisions (Tepeci and Bartlett, 2002), informed by employees' interests (Charlesworth et al., 2014; Muñoz de Bustillo et al., 2011), which are shaped by their social-cultural context such as personal lifestyle, relationships, values and experiences (Holman, 2013; Sledge et al., 2008). This desire for balance can be viewed in light of its contrast with the reality of employees' daily work experiences, in which it barely possible to combine professional and private aspirations (Richardson, 2009). The domestic convention, represented by "traditional work approach", is the second-most important attribute level within "notion of work". The importance to employees of preserving tradition, passing on experience and having "mutual trust" parallel the findings of Judge and Bretz (1992): that concern for others, mutual achievement and trust tend to have more influence on employees' perception of good job quality than do payment or promotional opportunities. Interestingly, the "reputation and public image" of the job is least important. Although other research works (Penny Wan et al., 2014; Kusluvan and Kusluvan, 2003) indicate that the social status of tourism and hospitality jobs is important for industry commitment, this study indicates that when choosing from different "personal notions of work", reputation and image are least relevant to employees. This finding can be attributed to the overall poor reputation of tourism and hospitality jobs (Blomme et al., 2008; Ramakrishnan and Macaveiu, 2019) and illustrates the reciprocal relationship between employees' preferences and the societal context in which they are embedded in. 
The study's findings that "work-related relationships" is ranked third by employees, whereas "career opportunities" is ranked fourth and "work tasks" is hardly important, partly contrast with earlier findings showing that one of the most-important drivers of job satisfaction for hospitality employees are career advancement opportunities (McPhail et al., 2015). Besides the overall importance of the green and/or domestic convention in four of the five job attributes, when it comes to career opportunities, the market convention attribute level of acquiring "skills demanded in the job market" is most important. This finding highlights the weakness of internal labour markets specific in the tourism and hospitality industry (Baum, 2008) and explains why tourism and hospitality employees, especially in small-scale Alpine-region entities, pursue skills in demand in the external labour market, hence rendering career opportunities within an organization less important.

In contrast to these general results, the smaller Cluster 1 ( 8.6 per cent) has an overall distinct preference for the market convention. This employee segment may mirror recent findings on the effects of the commercialization on hospitality employees (Golubovskaya et al., 2017), where value for money (Kandampully and Solnet, 2015) has become the dominant principle. Members of Cluster 1 also more often have parents who manage or own a hospitality business, possibly implying that their socialization lends itself to a focus on a market convention ("making business"), supporting their identification with their jobs and the industry in this specific way. Working for a family-owned-and-operated business might enhance these respondents' job embeddedness (Robinson et al., 2014) and person-organization fit (Song and Chathoth, 2011), as their jobs are more adequately designed to fit their preferences.

Overall, the two clusters depict tourism and hospitality employees' different and contradictory yet complementary job expectations: first, that jobs should provide a decent salary for a reasonable amount of working time and tasks (Cluster 1), which connects to research identifying salary as a key driver to industry commitment (Penny Wan et al., 2014); second, that jobs should allow private and professional life to be combined and should provide a feeling of belonging (Cluster 2). Cluster 2 connects to research indicating the importance employees place on stable working environments and on being taken care of (Kong et al., 2015), and to research indicating the importance of work-life balance (Deery and Jago, 2015). The greater prevalence of Cluster 2 compared to Cluster 1 indicates that money and career development is less important than previous research (Penny Wan et al., 2014; Kong et al., 2015) suggests.

\subsection{Theoretical implications}

This study reveals that different evaluative repertoires inform employees' evaluation of specific job attributes and are therefore an important factor for job attraction and job choice (see also Judge and Bretz, 1992). There have been - to date - no scholarly accounts of which social-cultural aspects underlie employees' job evaluations in the tourism and hospitality industry. This study contributes to a nuanced understanding of employees' attribute preferences and their evaluation of tourism and hospitality jobs in the following ways: First, the findings of this study supports research calling for sustainable employment relations (Baum, 2008) and for notions of mutual trust and tradition (Andersson et al., 2002). These results empirically reflect employees' strong preferences for green and domestic (family) conventions (Boltanski and Thévenot, 2006; Thévenot et al., 2000). According to some authors (Zhao and Ghiselli, 2016), employees evaluate jobs according to premises of belonging to an organization and contributing to its long-term sustainability, as they strive for high-trust relationships and family-like structures (see the notion of "work family" in Sturges, 2013), whereas others suggest that work features which foster the well-being of the worker (Green, 2006) and take employees' personal life values and lifestyle into account
Employees' evaluative repertoires

3185 
IJCHM

31,8

(Charlesworth et al., 2014) influence employees' job evaluations (Gallie et al., 2016), especially in the tourism and hospitality industry (Deery, 2008; Deery and Jago, 2009). This study adds to current research on job evaluation (McPhail et al., 2015) by embedding employees' job expectations in a broader social-cultural framework, which allows for a more nuanced explanation of variance in the importance to employees of common job attributes. This situated view implies that employees evaluate jobs according to the premises of the recursive constitution of their individual interests and a more general societal concern for such things as the sustainability or well-being of others.

Second, the homogeneity of employees' evaluative repertoires is theoretically interesting. Most important to employees are the green and domestic convention. From an EC perspective, this homogeneity conforms to Lamont and Thévenot (2000), who suggested that employees' job expectations evolve from features of the setting and the social-cultural environment in which they are embedded. As every institutional arrangement displays a specific set of conventions (Diaz-Bone, 2011; Thévenot, 2001), this paper shows that from an employee's perspective the green and the domestic (family) convention most prominently characterize the institutional arrangement of work and employment in the tourism and hospitality industry.

The prevalence of the domestic (family) convention can be understood in light of the context of an industry situated in an Alpine (mostly rural) setting made up of small-scale, mostly family-owned-and operated (Kallmuenzer, 2018) organizations. As for the domestic (family) convention, tradition and craftsmanship are important (Boltanski and Thévenot, 2006), and it can be argued that these are important features that characterize the product and the brand of tourism in this region, which then also become relevant in employment. The dominance of the green convention, though, is rather surprising since it has so far not been associated with work-related settings. Two specific aspects of the Alpine setting might help explain this finding: First, tourism and hospitality in this region are very much dependent on the natural environment and its regional products and employees (Strobl et al., 2015), whose sustainability is key to economic success (Kallmuenzer et al., 2017). Second and related - the green dimension also reflects recent increased attention on work-life balance in this industry (Deery and Jago, 2009; Ko et al., 2019). Hence, these findings suggest a connection between the type of work (tourism and hospitality jobs), the type of organization and industry (small-scale, mostly family-owned-and-operated) and the prevalent conventions and evaluative repertoires. This study thus contributes to EC research by more specifically characterizing the setting of tourism and hospitality employment and by operationalizing the framework to envision the connection between job, industry and conventions and thus empirically confirming actors' embeddedness in a broader social-cultural framework.

\subsection{Practical implications}

The findings of this study will help tourism and hospitality employers to better manage employee talents (Baum, 2008, 2015; Deery and Jago, 2009, 2015) by enhancing employers' understanding of their current and prospective employees and helping them design jobs and job offerings that better fit workers' preferences and expectations. Tourism and hospitality employers in general, and human resource managers specifically, play a key role (Baum, 2008), as they have the authority to (and need to) significantly alter job attributes and working conditions to differentiate themselves in an industry with an overall negative reputation and a volatile workforce. This study's findings suggest several practical implications for improving tourism and hospitality organizations' recruitment and retention.

For recruitment, tourism and hospitality employers should adapt their job postings to attract more applicants (Ladkin and Buhalis, 2016). For instance, as employees look for 
combinations of the green and domestic (family) convention characteristics when assessing job offers, and while job postings are usually very brief, the findings strongly suggest that employers should emphasise and expand the "benefits" section of their job postings, explicitly offering flexible working hours and explaining precisely how they help employees balance professional and private life. This might also include offering child care or continuous (instead of split) shifts and providing industry-acknowledged skill-development programs. Furthermore, the job posting should communicate an employment relationship characterized by mutual trust and an appreciation of every single employee, whose work will continue and preserve the tradition of the profession and the company.

To retain employees, this study's findings suggest that tourism and hospitality businesses must adapt their jobs to match employees' ideal job preferences and enhance job embeddedness (Robinson et al., 2014) and person-organization fit (Song and Chathoth, 2011). The set of preferred identified job descriptions can serve as a starting point for adapting jobs. Overall, designing jobs according to green and domestic (family) convention characteristics facilitates organizational socialization (Song et al., 2015) and contributes to job satisfaction. Corporate culture should focus on sustainability, both in terms of the business and the employment relationships. This kind of sustainability would involve rethinking employment regimes, including changing contracts from seasonal to all-year work, allowing employees to have a job in the same region throughout the year or redesigning work schedules to respond to employee and customer demands. These changes would help employees balance their private and professional aspirations.

A final practical implication is that corporate culture should focus on building and developing a sense of belonging and trust among colleagues and with the company. One way to do so would be to include individual employees in corporate product communication, as employees are the ones who actually produce the high service quality and maintain the regional traditions customers expect. Furthermore, just as customer relationships are managed, fostering long-term relationships with employees - even seasonal ones - can make them feel integrated and make it easier to retain them. Although these are general suggestions, members of Cluster 1 might especially value opportunities to take part in and contribute to the company's overall business success. This could be achieved by organizing tourism and hospitality businesses as cooperatives, issuing shares for employees or allowing them to participate in the company's profit.

\subsection{Limitations and future research}

This study has a few limitations. First, to simplify the job descriptions, and for methodical constraints, only four (out of eight possible) conventions were selected for the conjoint analysis. Further research can include other conventions, such as the industrial or network convention, to gain a more comprehensive picture of employees' preferences.

Second, the paper assumed that an additive composition rule was appropriate and that no interaction terms were needed. Consequently, only choice sets with no level overlaps were presented. Thus, only main effects were estimated. Future research can address interaction effects between job attributes.

Third, future research should investigate the antecedents and variations in the envisioned connection between the type of work (tourism and hospitality jobs), the type of organization/industry, culture and the prevalent conventions and evaluative repertoires. Our findings suggest that in other jobs in other industries, such as banking and finance, a different set of conventions characterizes the setting. The sample from a singular cultural context, the Tyrolean Alpine region, therefore presents a limitation. While in this study the "green" and the "domestic (family)" conventions stand out, preferences might be different in

Employees' evaluative repertoires 
IJCHM 31,8

other tourism regions around the world (see for example Park et al., 2017 for the Korean context, or Sledge et al., 2008 for the Brazilian context). Future research could investigate the effects of socialization in different contexts over time, such as working for employers in different organizational cultures or regions. In-depth qualitative accounts are needed to further confirm and elaborate on the meaning of work for tourism and hospitality employees, particularly given the prevalent conventions indicated here.

Fourth, future studies should examine the influence of the degree-of-fit between value and job-attribute preferences and employees' current jobs on outcomes such as job satisfaction and job duration. Drawing on research on person-organization fit (Song et al., 2015; Song and Chathoth, 2011), job embeddedness (Robinson et al., 2014) and organizational commitment (Zopiatis et al., 2014), we speculate that job satisfaction increases when employers adapt their jobs to fit to employees' values and job attribute preferences.

\section{References}

Aguinis, H. and Bradley, K.J. (2014), "Best practice recommendations for designing and implementing experimental vignette methodology studies", Organizational Research Methods, Vol. 17 No. 4, pp. 351-371.

Aizaki, H. (2012), "Basic functions for supporting an implementation of choice experiments in R", Journal of Statistical Software, Vol. 50, pp. 1-24.

AMS (2015), Skilled Labour Shortage in Austria: Results of the AMS Enterprise Survey 2013/14, Public Employment Service, Vienna.

Andersson, T., Carlsen, J. and Getz, D. (2002), "Family business goals in the tourism and hospitality sector: case studies and cross-case analysis from Australia, Canada and Sweden”, Family Business Review, Vol. 15 No. 2, pp. 89-106.

Baum, T. (2008), "Implications of hospitality and tourism labour markets for talent management strategies", International Journal of Contemporary Hospitality Management, Vol. 20 No. 7, pp. $720-729$.

Baum, T. (2015), "Human resources in tourism: still waiting for change? - A 2015 reprise", Tourism Management, Vol. 50, pp. 204-212.

Bellou, V., Stylos, N. and Rahimi, R. (2018), "Predicting hotel attractiveness via personality traits of applicants", International Journal of Contemporary Hospitality Management, Vol. 30 No. 10, pp. 3135-3155.

Blomme, R.J., Tromp, D.M. and Van Rheede, A. (2008), "Predictors of turnover intentions of highly-educated employees in the hospitality industry", Advances in Hospitality and Leisure, Vol. 4, pp. 3-28.

Boltanski, L. and Thévenot, L. (2006), On Justification: Economies of Worth, Princeton University Press, Princeton, NJ.

Brandl, J., Kozica, A., Pernkopf, K. and Schneider, A. (2019), "Flexible work practices: analysis from a pragmatist perspective", Historical Social Research, Vol. 44 No. 1, pp. 73-91.

Bullinger, B. and Treisch, C. (2015), "Herding cats: future professionals' expectations of attractive employers", Zeitschrift Für Personalforschung, Vol. 29 No. 2, pp. 149-177.

Charlesworth, S., Welsh, J., Strazdins, L., Baird, M. and Campbell, I. (2014), "Measuring poor job quality amongst employees: the VicWAL job quality index", Labour and Industry: A Journal of the Social and Economic Relations of Work, Vol. 24 No. 2, pp. 103-123.

Davidson, M.C., McPhail, R. and Barry, S. (2011), "Hospitality HRM: past, present and the future", International Journal of Contemporary Hospitality Management, Vol. 23 No. 4, pp. 498-516.

Day, J., Karani, A., Adler, H. and Nicely, A.M. (2013), "Corporate social responsibility and college recruiting in the hospitality industry", Journal of Human Resources in Hospitality and Tourism, Vol. 12 No. 1, pp. 71-90. 
Deery, M. (2008), "Talent management, work-life balance and retention strategies", International Journal of Contemporary Hospitality Management, Vol. 20 No. 7, pp. 792-806.

Deery, M. and Jago, L. (2009), "A framework for work-life balance practices: addressing the needs of the tourism industry", Tourism and Hospitality Research, Vol. 9 No. 2, pp. 97-108.

Employees' evaluative repertoires

Deery, M. and Jago, L. (2015), "Revisiting talent management, work-life balance and retention strategies", International Journal of Contemporary Hospitality Management, Vol. 27 No. 3, pp. 453-472.

Diaz-Bone, R. (2011), "The methodological standpoint of the "économie des conventions", Historical Social Research/Historische Sozialforschung, Vol. 36 No. 4, pp. 43-63.

Eurostat (2018), "Tirol: Introduction", available at: https://ec.europa.eu/growth/tools-databases/ regional-innovation-monitor/base-profile/tyrol (accessed 13 March 2019).

Gallie, D., Gebel, M., Giesecke, J., Halldén, K., van der Meer, P. and Wielers, R. (2016), "Quality of work and job satisfaction: comparing female part-time work in four European countries", International Review of Sociology, Vol. 26 No. 3, pp. 457-481.

Golubovskaya, M., Robinson, R. and Solnet, D. (2017), "The meaning of hospitality: do employees understand?", International Journal of Contemporary Hospitality Management, Vol. 29 No. 5, pp. 1282-1304.

Green, F. (2006), Demanding Work: The Paradox of Job Quality in the Affluent Economy, Princeton University Press, Princeton, NJ.

Guillet, B.D. and Kucukusta, D. (2016), "Spa market segmentation according to customer preference", International Journal of Contemporary Hospitality Management, Vol. 28 No. 2, pp. 418-434.

Guillot-Soulez, C. and Soulez, S. (2014), "On the heterogeneity of generation Y job preferences", Employee Relations, Vol. 36 No. 4, pp. 319-332.

Hair, J.F., Black, W.C., Babin, B.J. and Anderson, R.E. (2010), Multivariate Data Analysis, 7th ed., Pearson, New York, NY.

Holman, D. (2013), "Job types and job quality in Europe", Human Relations, Vol. 66 No. 4, pp. 475-502.

Judge, T.A. and Bretz, R.D. Jr, (1992), "Effects of work values on job choice decisions", Journal of Applied Psychology, Vol. 77 No. 3, pp. 261-271.

Kalleberg, A.L. (2008), "The mismatched worker: when people don't fit their jobs", Academy of Management Perspectives, Vol. 22 No. 1, pp. 24-40.

Kallmuenzer, A. (2018), "Exploring drivers of innovation in hospitality family firms", International Journal of Contemporary Hospitality Management, Vol. 30 No. 3, pp. 1978-1995.

Kallmuenzer, A., Nikolakis, W., Peters, M. and Zanon, J. (2017), "Trade-offs between dimensions of sustainability: exploratory evidence from family firms in rural tourism regions", Journal of Sustainable Tourism, pp. 1-18.

Kandampully, J. and Solnet, D. (2015), Service Management Principles for Hospitality and Tourism, 2nd ed., Kendall Hunt, Des Moines, IA.

Knox, A., Warhurst, C., Nickson, D. and Dutton, E. (2015), "More than a feeling: using hotel room attendants to improve understanding of job quality", The International Journal of Human Resource Management, Vol. 26 No. 12, pp. 1547-1567.

Ko, A., Chan, A. and Wong, S.C.K. (2019), "A scale development study of CSR: hotel employees' perceptions", International Journal of Contemporary Hospitality Management, Vol. 31 No. 4, pp. 1857-1884, available at: https://doi.org/10.1108/IJCHM-09-2017-0560

Kong, H., Wang, S. and Fu, X. (2015), "Meeting career expectation: can it enhance job satisfaction of generation Y?", International Journal of Contemporary Hospitality Management, Vol. 27 No. 1, pp. 147-168.

Kong, H., Jiang, X., Chan, W. and Zhou, X. (2018), "Job satisfaction research in the field of hospitality and tourism", International Journal of Contemporary Hospitality Management, Vol. 30 No. 5, pp. 2178-2194. 


\section{IJCHM 31,8}

Kusluvan, S. and Kusluvan, Z. (2003), "Perceptions and attitudes of undergraduate tourism students towards working in the tourism and hospitality industry in a developing economy", in Kusluvan, S. (Ed.), Managing Employee Attitudes and Behaviors in the Tourism and Hospitality Industry, Nova Science, New York, NY, pp. 77-98.

Ladkin, A. and Buhalis, D. (2016), "Online and social media recruitment: hospitality employer and prospective employee considerations", International Journal of Contemporary Hospitality Management, Vol. 28 No. 2, pp. 327-345.

Lamont, M. and Thévenot, L. (Eds) (2000), Rethinking Comparative Cultural Sociology: Repertoires of Evaluation in France and the United States, Cambridge University Press, Cambridge.

Luce, R.D. and Tukey, J.W. (1964), "Simultaneous conjoint measurement: a new type of fundamental measurement", Journal of Mathematical Psychology, Vol. 1 No. 1, pp. 1-27.

McPhail, R., Patiar, A., Herington, C., Creed, P. and Davidson, M. (2015), "Development and initial validation of a hospitality employees' job satisfaction index", International Journal of Contemporary Hospitality Management, Vol. 27 No. 8, pp. 1814-1838.

Montgomery, D.B. and Ramus, C.A. (2011), "Calibrating MBA job preferences for the 21st century", Academy of Management Learning and Education, Vol. 10 No. 1, pp. 9-26.

Muñoz de Bustillo, R., Fernandez-Macias, E., Esteve, F. and Anton, J.I. (2011), "E pluribus Unum? A critical survey of job quality indicators", Socio-Economic Review, Vol. 9 No. 3, pp. 447-475.

Nykiel, R.A. (2005), Hospitality Management Strategies, Prentice Hall, Upper Saddle River, NJ.

Okumus, F., Altinay, L. and Chathoth, P. (2010), Strategic Management for Hospitality and Tourism, Butterworth-Heinemann, Amsterdam.

Park, S., Kim, H. and Lee, K. (2017), "Perceptions of determinants of job selection in the hospitality and tourism industry: the case of Korean university students", Journal of Human Resources in Hospitality and Tourism, Vol. 16 No. 4, pp. 422-444.

Patriotta, G., Gond, J.B. and Schultz, F. (2011), "Maintaining legitimacy: controversies, orders of worth, and public justifications", Journal of Management Studies, Vol. 48 No. 8, pp. 1804-1836.

Penny Wan, Y.K., Wong, I.A. and Kong, W.H. (2014), "Student career prospect and industry commitment: the roles of industry attitude, perceived social status, and salary expectations", Tourism Management, Vol. 40, pp. 1-14.

Pernkopf-Konhäusner, K. and Brandl, J. (2011), "Variations in evaluative repertoires: comparing employee perspectives on training and development in Germany and Russia”, Personnel Review, Vol. 40 No. 6, pp. 589-606.

Peters, M. and Frehse, J. (2011), "Small and family businesses as service brands: an empirical analysis in the hotel industry", International Journal of Entrepreneurship and Small Business, Vol. 12 No. 1, pp. $28-43$.

Ramakrishnan, S. and Macaveiu, C. (2019), "Understanding aspirations in tourism students", Journal of Hospitality and Tourism Management, Vol. 39, pp. 40-48.

Richardson, S. (2009), "Undergraduates' perceptions of tourism and hospitality as a career choice", International Journal of Hospitality Management, Vol. 28 No. 3, pp. 382-388.

Robinson, R.N.S., Kralj, A., Solnet, D.J., Goh, E. and Callan, V. (2014), "Thinking job embeddedness not turnover: towards a better understanding of frontline hotel worker retention", International Journal of Hospitality Management, Vol. 36, pp. 101-109.

Rossi, P.E., Allenby, G.M. and McCulloch, R. (2005), Bayesian Statistics and Marketing, Wiley, Hoboken, NJ.

Schoffstall, D.G. and Arendt, S.W. (2016), "Hospitality students' work experiences and an examination of their perceptions of the future", Journal of Human Resources in Hospitality and Tourism, Vol. 15 No. 2, pp. 209-229.

Sledge, S., Miles, A.K. and Coppage, S. (2008), "What role does culture play? A look at motivation and job satisfaction among hotel workers in Brazil", The International Journal of Human Resource Management, Vol. 19 No. 9, pp. 1667-1682. 
Song, Z. and Chathoth, P.K. (2011), "Intern newcomers' global self-esteem, overall job satisfaction, and choice intention: person-organization fit as a mediator", International Journal of Hospitality Management, Vol. 30 No. 1, pp. 119-128.

Song, Z., Chon, K., Ding, G. and Gu, C. (2015), "Impact of organizational socialization tactics on newcomer job satisfaction and engagement: core self-evaluations as moderators", International Journal of Hospitality Management, Vol. 46, pp. 180-189.

Strobl, A., Teichmann, K. and Peters, M. (2015), "Do Mountain tourists demand ecotourism? Examining moderating influences in an alpine tourism context", Turizam, Vol. 63 No. 3, pp. 383-398.

Employees'

evaluative

repertoires

Sturges, J. (2013), “A matter of time: young professionals' experiences of long work hours”, Work, Employment and Society, Vol. 27 No. 2, pp. 343-359.

Suzuki, R. and Shimodaira, H. (2006), "Pvclust: an R package for assessing the uncertainty in hierarchical clustering", Bioinformatics, Vol. 22 No. 12, pp. 1540-1542.

Tepeci, M. and Bartlett, A. (2002), "The hospitality industry culture profile: a measure of individual values, organizational culture, and person-organization fit as predictors of job satisfaction and behavioral intentions", International Journal of Hospitality Management, Vol. 21 No. 2, pp. 151-170.

Thévenot, L. (2001), "Organized complexity: conventions of coordination and the composition of economic arrangements", European Journal of Social Theory, Vol. 4 No. 4, pp. 405-425.

Thévenot, L., Moody, M. and Lafaye, C. (2000), "Forms of valuing nature: arguments and modes of justification in French and American environmental disputes", in Lamont, M. and Thévenot, L. (Eds), Rethinking Comparative Cultural Sociology: Repertoires of Evaluation in France and the United States, Cambridge University Press, Cambridge, pp. 229-272.

Wrzesniewski, A. and Dutton, J. (2001), "Crafting a job: revisioning employees as active crafters of their work", Academy of Management Review, Vol. 26 No. 2, pp. 179-201.

Yen, C., Chen, C. and Teng, H. (2013), "Perceptions of environmental management and employee job attitudes in hotel firms", Journal of Human Resources in Hospitality and Tourism, Vol. 12 No. 2, pp. 155-174.

Zhao, X. and Ghiselli, R. (2016), "Why do you feel stressed in a 'smile factory'? Hospitality job characteristics influence work-family conflict and job stress", International Journal of Contemporary Hospitality Management, Vol. 28 No. 2, pp. 305-326.

Zopiatis, A., Constanti, P. and Theocharous, A.L. (2014), "Job involvement, commitment, satisfaction and turnover: evidence from hotel employees in Cyprus", Tourism Management, Vol. 41, pp. 129-140.

\section{Corresponding author}

Anna Schneider can be contacted at: anna.schneider@uibk.ac.at

For instructions on how to order reprints of this article, please visit our website:

www.emeraldgrouppublishing.com/licensing/reprints.htm

Or contact us for further details: permissions@emeraldinsight.com 